OPEN ACCESS

Edited by:

Chantal Raherison,

Université de Bordeaux, France

Reviewed by:

Michael Calik,

University of Illinois at Chicago,

United States

Dalva Poyares,

Federal University of São Paulo, Brazil

${ }^{*}$ Correspondence:

Alberto Alonso-Fernández aaf_97@hotmail.com

Specialty section: This article was submitted to

Pulmonary Medicine,

a section of the journal

Frontiers in Medicine

Received: 02 March 2021 Accepted: 24 September 2021 Published: 02 November 2021

Citation:

Alonso-Fernández A, Ribot Quetglas C, Herranz Mochales A Álvarez Ruiz De Larrinaga A, Sánchez Barón A, Rodríguez Rodríguez P, Gil Gómez AV, Pía Martínez C, Cubero Marín JP, Barceló Nicolau M, Cerdà Moncadas M, Codina Marcet M, De

La Peña Bravo M, Barceló

Bennasar A, Iglesias Coma A,

Morell-Garcia D, Peña Zarza JA,

Giménez Carrero MP, Durán

Cantolla J, Marín Trigo JM, Piñas

Cebrian MC, Soriano JB and

García-Río $F$ (2021) Influence of Obstructive Sleep Apnea on Systemic

Inflammation in Pregnancy.

Front. Med. 8:674997.

doi: 10.3389/fmed.2021.674997

\title{
Influence of Obstructive Sleep Apnea on Systemic Inflammation in Pregnancy
}

\begin{abstract}
Alberto Alonso-Fernández ${ }^{1,2,3 *}$, Caterina Ribot Quetglas ${ }^{1}$, Andrea Herranz Mochales ${ }^{1}$, Ainhoa Álvarez Ruiz De Larrinaga ${ }^{4,5}$, Andrés Sánchez Barón ${ }^{6}$, Paula Rodríguez Rodríguez ${ }^{5}$, Ana Victoria Gil Gómez ${ }^{7}$, Carla Pía Martínez ${ }^{5}$, José Pablo Cubero Marín ${ }^{7}$, Maria Barceló Nicolau ${ }^{1}$, María Cerdà Moncadas ${ }^{8}$, Mercedes Codina Marcet ${ }^{9}$, Mónica De La Peña Bravo ${ }^{1,2,3}$, Antònia Barceló Bennasar ${ }^{1,10}$, Amanda Iglesias Coma ${ }^{1,3}$, Daniel Morell-Garcia ${ }^{1,10}$, José Antonio Peña Zarza ${ }^{11}$, María Paloma Giménez Carrero ${ }^{1}$, Joaquín Durán Cantolla ${ }^{4,5}$, José María Marín Trigo ${ }^{6,7}$, María Concepción Piñas Cebrian ${ }^{1,2}$, Joan B. Soriano ${ }^{3,12}$ and Francisco García-Río ${ }^{13}$

${ }^{1}$ Institut d'Investigació Sanitària Illes Balears (IdISBa), Palma, Spain, ${ }^{2}$ Servicio de Neumología, Hospital Universitari Son Espases, Palma, Spain, ${ }^{3}$ Centro de Investigación Biomédica en Red de Enfermedades Respiratorias (CIBERES), Madrid, Spain, ${ }^{4}$ Unidad del Sueño, Hospital Universitario de Araba, Vitoria-Gasteiz, Spain, ${ }^{5}$ Instituto de Investigación BIOARABA, Vitoria-Gasteiz, Spain, ${ }^{6}$ Servicio de Neumología, Hospital Universitario Miguel Servet, Zaragoza, Spain, ${ }^{7}$ Instituto de Investigación Sanitaria de Aragón, Hospital Universitario Miguel Servet, Zaragoza, Spain, ${ }^{8}$ Servicio de Neumología, Hospital Palma Planas, Palma, Spain, ${ }^{9}$ Servicio de Endocrinología, Hospital Universitari Son Espases, Palma, Spain, ${ }^{10}$ Servicio de Análisis Clínicos, Hospital Universitari Son Espases, Palma, Spain, " Servicio de Pediatría, Hospital Universitari Son Espases, Palma, Spain, ${ }^{12}$ Hospital Universitario La Princesa, Universidad Autónoma de Madrid, Madrid, Spain, ${ }^{13}$ Servicio de Neumología, Hospital Universitario La Paz, Instituto de Investigación del Hospital Universitario La Paz (IdiPAZ), Madrid, Spain
\end{abstract}

Background: Obstructive sleep apnea (OSA) is prevalent in pregnancy and it is associated with adverse pregnancy-related outcomes such as gestational diabetes, pre-eclampsia, and low birth weight. Maternal systemic inflammation is proposed to be one of the main intermediate mechanisms. However, the effects of OSA on systemic inflammation are unknown in normal pregnancy.

Methods: Women in the 3rd trimester underwent hospital polysomnography to evaluate whether OSA increases systemic inflammation in normal pregnancy and its potential association with adverse fetal outcomes. OSA was defined as an apnea-hypopnea index $(\mathrm{AHI})$ of $\geq 5 \mathrm{~h}^{-1}$. Plasma cytokines levels (TNF- $\alpha, \mathrm{IL}-1 \beta, \mathrm{IL}-6, \mathrm{IL}-8$, and IL-10) were determined by multiple immunoassays.

Results: We included 11 patients with OSA and 22 women with $\mathrm{AHI}<5 \mathrm{~h}^{-1}$, who were homogeneous in age, and body mass index (BMI). Women with OSA had significant higher levels of TNF- $\alpha, I L-1 \beta, I L-8$, and IL-10. We found significant correlations between AHI during REM and TNF- $\alpha(r=0.40), I L-1 \beta(r=0.36), I L-6(r=0.52), I L-8$ $(r=0.43)$, between obstructive apnea index and TNF- $\alpha(r=0.46)$ and between AHI and IL-1 $\beta(r=0.43)$. We also found that CT90\% was related to IL-8 $(r=0.37)$. There were no significant differences in neonatal characteristics; however, we found inverse correlations between TNF- $\alpha$ and IL-8 with birth weight (both $r=-0.48$ ), while IL-8 showed a significant inverse relationship with neonatal gestational age $(r=-0.48)$. 
Conclusions: OSA in our normal pregnancy population was associated with higher systemic inflammation, which was related to obstructive events, especially during REM sleep. Moreover, systemic inflammation was inversely correlated with neonatal birth weight and age.

Keywords: apneas-hypopneas index, hypoxia, fetal outcomes, REM, cytokine, inflammation, Obstructive sleep apnea

\section{INTRODUCTION}

Obstructive sleep apnea (OSA) is a common disorder characterized by the presence of repetitive episodes of total (apneas) or partial (hypopneas) airflow cessation in the upper airway during sleep despite increased respiratory effort (1). Apneas and hypopneas are frequently accompanied by a decrease in arterial oxygen saturation that normalizes with breathing resumption producing repeated cycles of hypoxiareoxygenation (2), which are associated to an increase in pro-inflammatory cytokines in general population $(3,4)$. These cytokines are secreted in different tissues, including adipose tissue in a close relationship between obesity and OSA. Obesity is the primary risk factor for OSA. In fact, other studies have already shown the relationship between weight gain and the risk of OSA or increasing its severity (5).

Prevalence of OSA during pregnancy increases due to some physiological changes, such as weight gain or modifications in the upper airway $(6,7)$. OSA is associated with adverse pregnancy outcomes such as gestational diabetes mellitus (GDM) (8-10), pre-eclampsia (8), gestational hypertension (11), and with fetal related outcomes $(12,13)$, preterm birth, and neonatal low weight (14). Normal pregnancy is associated with higher inflammation markers compared to non-pregnant women (15-17). Patients with GDM or pre-eclampsia show further increments in inflammation levels (18-21). There are also significant associations between maternal systemic inflammation and neonatal low birth weight $(20,22)$ even though more studies are clearly required to clarify the influence of important confounding factors such as obesity, age and comorbidities. It has been proposed that increments in systemic inflammation (23) are one of the main mechanisms that associate OSA with adverse pregnancy outcomes. However, no studies have assessed the effect of OSA on systemic inflammation in uncomplicated pregnancies so far.

The study aims were: (1) to evaluate the levels of inflammatory cytokines (tumor necrosis factor alpha (TNF- $\alpha$ ), interleukin 1 beta (IL-1 $\beta$ ), interleukin 6 (IL-6), interleukin 8 (IL-8), and

Abbreviations: AHI, Apnea-hypopnea index; ALT, Alanine aminotransferase; AST, Aspartate aminotransferase; BMI, Body mass index; BP, Blood pressure; CT90\%, Sleep time with oxygen saturation <90\%; GDM, Gestational diabetes mellitus; GGT, Gamma-glutamyl transpeptidase; HDL, High-density lipoprotein; HOMA-IR, Homeostatic model assessment of insulin resistance; IH, Intermittent hypoxia; IL, Interleukin; IQR, Interquartile range; LDL, Low-density lipoprotein; OAI, Obstructive apnea index; OSA, Obstructive sleep apnea; PSG, Polysomnography; REM, Rapid eye movement; Sd, Standard deviation; $\mathrm{SpO}_{2}$, Oxygen saturation; TG, Triglycerides; TNF- $\alpha$, Tumor necrosis factor alpha; TST, Total sleep time. interleukin 10 (IL-10) in OSA and healthy pregnant women who were homogeneous in age, and body mass index (BMI) in the third trimester; (2) to relate systemic inflammation with adverse maternal and fetal outcomes.

\section{MATERIALS AND METHODS Subjects and Study Design}

Women were recruited at three tertiary and university hospitals in Spain (Hospital Universitari Son Espases, Hospital Universitario Araba and Hospital Universitario Miguel Servet). Inclusion criteria were: (1) singleton pregnant women in the third trimester of pregnancy, and (2) signed an informed consent (IC). Patients were excluded if they fulfilled at least one of the following exclusion criteria: (1) previous OSA diagnosis, (2) glucose value at $1 \mathrm{~h}$ after a 50 -g oral glucose administration that did exceed $140 \mathrm{mg} / \mathrm{dL}$, (3) complicated pregnancy (gestational hypertension, GDM, pre-eclampsia, and any other significant obstetrical complication), (4) previous diabetes mellitus, pulmonary, cardiac, or kidney diseases, (5) treatment with steroids, (6) unwillingness or inability to participate in the study, (7) imminent delivery due to maternal-fetal disease; and/or (8) any other concurrent severe medical condition that would, in the investigators' judgment, contraindicate patient participation in the study. Women were selected from a large study evaluating consequences of OSA during pregnancy. Based on previous studies reporting plasma TNF- $\alpha$ levels of $4.6 \pm 0.6 \mathrm{pg} / \mathrm{mL}$ in non-complicated third trimester of pregnancy (24) with an alpha risk of 0.05 and a beta risk in a two-way contrast, 22 healthy pregnant women and 11 pregnant women with OSA are required to detect a difference equal to or $>0.63 \mathrm{pg} / \mathrm{mL}$ (14\% of mean value).

\section{Ethics Statement}

The study was approved by the Institutional Ethics Committee of the hospitals and all subjects gave their written informed consent.

Each patient had their anthropometric, clinical, and sleep data collected by means of questionnaires and direct measurements that included: age, body mass index, co-morbidities and alcohol intake and tobacco consumption. Neck, waist, and hip circumferences were measured at the levels of the cricothyroid membrane, at the point equidistant between the iliac crest and the lowest rib, and at the point of greater trochanter, respectively. Office blood pressure was measured by a randomzero sphygmomanometer with appropriate sized cuff, with the individual seated for at least $5 \mathrm{~min}$. Recorded values were the mean of three readings. 
Episodes of subjective gasping, snoring, bed partner-reported sleep breathing pauses, nocturia, morning headache, morning tiredness, and sleepiness while driving were collected in four degrees of intensity (never, sometimes, frequently, and always) based on the previous 4 weeks. Subjective nocturnal sleep time as well as napping time on working days and weekends along with daytime sleepiness [using the Epworth sleepiness scale (ESS) (25)] based on the previous 4 weeks were ascertained. Daytime sleepiness was defined as an ESS $\geq 11$.

\section{Polysomnography (PSG)}

Overnight-attended PSG was performed in the sleep laboratory. Electroencephalogram (C3-A2, C4-A1), electrooculogram, chin electromyogram, electromyograms of the tibialis anterior of both legs and electrocardiogram were continuously recorded. Breathing was monitored using nasal cannulas, oronasal thermistors, and thoracoabdominal strain gauges. Simultaneously, oxyhemoglobin saturation $\left(\mathrm{SpO}_{2}\right)$ was monitored with a pulse oximeter. Sleep was analyzed using the standard criteria for epochs of $30 \mathrm{~s}$ (26). Apnea was defined as the absence of airflow ( $>90 \%$ reduction) for at least $10 \mathrm{~s}$ while hypopnea was defined as a discernible airflow reduction $(>30 \%$ and $<90 \%$ ) for at least $10 \mathrm{~s}$ with $\mathrm{a} \geq 3 \%$ drop in oxygen saturation or final arousal. The events were considered obstructive in the presence of continued respiratory efforts. The apneas-hypopneas index (AHI) was established as the number of apneas and hypopneas per hour of sleep. OSA was defined as an AHI of $\geq 5$ $\mathrm{h}^{-1}$ (27). REM AHI was calculated as the number of apneas and hypopneas during REM sleep divided by total time in REM sleep in hours. As indices of nocturnal oxygen saturation, the medium $\mathrm{SpO}_{2}$ throughout the night, the minimum $\mathrm{SpO}_{2}$ (lowest values recorded during sleep) and total time study spent with $\mathrm{SpO}_{2}<$ 90\% (CT90\%) were computed.

\section{Blood Sample Collection and Determinations}

The morning after the PSG, anthropometric variables, and blood samples were collected from all women in fasting conditions. Laboratory data included complete blood count (Cell-Dyn Sapphire Platform, Abbott Diagnostics), coagulation, kidney and liver function tests (Architect c16000 platform. Abbott Diagnostics, US). Insulin was determined by processing serum samples on the Cobas e-411 platform (Roche Diagnostics $\mathrm{GmbH}$, Germany) with a reference range of 3-25 $\mu \mathrm{UI} / \mathrm{mL}$. The Homeostatic model assessment of insulin resistance index (HOMA-IR) was calculated by the usual formula (28).

The remaining blood sample was centrifuged at 2,500 rpm for $10 \mathrm{~min}$ to isolate the plasma. The different plasma aliquots were stored at $-80^{\circ} \mathrm{C}$ for further determinations.

The inflammatory cytokines were analyzed on plasma samples by multiplex technique using the Human High Sensitivity Cytokine Base Kit A (Magnetic Luminex $($ Performance Assay, $\mathrm{R} \& \mathrm{D}$ Systems $(\mathrm{R}$, Inc.) following the indicated procedure. For each one of the cytokines, analyzed the detection limits and coefficients of variation were $0.29 \mathrm{pg} / \mathrm{mL}$ and $5.2 \%$ (TNF- $\alpha$ ), 0.08 $\mathrm{pg} / \mathrm{mL}$ and $5.3 \%$ (IL-1 $\beta$ ), $0.14 \mathrm{pg} / \mathrm{mL}$ and $5.2 \%$ (IL-6), $0.04 \mathrm{pg} / \mathrm{mL}$ and $6.6 \%$ (IL-8), $0.21 \mathrm{pg} / \mathrm{mL}$ and $5.4 \%$ (IL-10).
Following the delivery day, anthropometric and neonatal variables were collected from all newborns. Laboratory researchers were blinded to maternal status.

\section{Statistical Analysis}

Data are presented as mean \pm standard deviation, median + interquartile range (IQR) or percentage. Differences between groups were analyzed using Student's $t$-test or $U$ Mann-Whitney test for continuous variables, and Fisher's exact test (two-tailed) or chi-squared test for categorical variables. As total sleep time (TST) was significantly different between apneic and non-apneic pregnant women, plasma levels of inflammatory biomarkers were corrected using a General Linear Model univariate procedure with group (OSA vs. non-OSA) as a fixed-effect factor and TST as a covariate factor. Moreover, inflammatory biomarkers were corrected using a General Linear Model univariate procedure with group (OSA vs. non-OSA) as a fixed-effect factor, and BMI before pregnancy and gestational age at plasma sampling, and BMI and gestational age at plasma sampling as covariate factors, respectively. Pearson's and Spearman's correlation tests examined correlations between variables. A two-sided $P<0.05$ was considered significant.

\section{RESULTS}

\section{Subjects Study}

To obtain the sample size pre-determined for the experimental group, and to include 11 pregnant women classified as OSA, we required assessing for eligibility 130 pregnant women, 42 were not selected ( 25 refused, 1 technical sleep study dropout, 1 twin pregnancy, 4 delivery before PSG, 1 change of address), and we finally needed to perform PSG to 88 women. We selected 22 women among the remaining non-OSA group, who were homogeneous in age, and body mass index (BMI) for comparative purposes. All 33 pregnant women were Caucasian except for one Hispanic. The descriptive analysis of both groups for their main anthropometric and clinical variables as well as the laboratory findings are shown in Table 1. The anthropometric characteristics, smoking status, nulliparous percentages, number of previous pregnancies, and blood pressure did not differ between patients with OSA and controls. Plasmatic fasting glucose levels were higher in non-OSA women than in the OSA group.

We included 11 pregnant women with OSA (AHI median 7.8 (IQR 5.6-9.7) $\mathrm{h}^{-1}$ ) and 22 non-OSA (AHI median 0.35 (IQR 0.07-0.7) $\mathrm{h}^{-1}$ ). Table 2 illustrates differences in PSG characteristics, symptoms and anthropometrics between groups. TST was longer in non-OSA women than in OSA subjects. As expected, there were significant differences between groups in the AHI, REM AHI, the obstructive apneas index (OAI), the desaturations index, and minimum $\mathrm{SpO}_{2}$ (Table 2). Three women had ESS $\geq 11$, and all of which presented AHI $<5$ $\mathrm{h}^{-1}$. No differences were found in daytime somnolence, snoring, episodes of subjective asphyxia, nocturia, morning headache, reported apneas, unrefreshing sleep, and reported sleep time 
TABLE 1 | General characteristics of pregnancy women with and without OSA.

\begin{tabular}{|c|c|c|c|c|c|}
\hline Variables & & Total & OSA $(n=11)$ & Non-OSA $(n=22)$ & $p$-value \\
\hline Age (years) & & $35 \pm 3.9$ & $33.9 \pm 5$ & $35.6 \pm 3.1$ & $0.245^{¥}$ \\
\hline Gestational age (weeks) at plasma sampling & & $33.5 \pm 3$ & $34.5 \pm 3$ & $33.1 \pm 3$ & $0.230^{¥}$ \\
\hline BMI before pregnancy $\left(\mathrm{Kg} / \mathrm{m}^{2}\right)$ & & $22.6 \pm 3.4$ & $23 \pm 3.4$ & $22.4 \pm 3.4$ & $0.641^{¥}$ \\
\hline Obese before pregnancy $n(\%)$ & & $2(6.1)$ & 0 & $2(9.1)$ & $0.542^{\infty}$ \\
\hline $\mathrm{BMI}$ at plasma sampling $\left(\mathrm{Kg} / \mathrm{m}^{2}\right)$ & & $26.8 \pm 2.9$ & $27.2 \pm 2.4$ & $26.6 \pm 3.2$ & $0.555^{¥}$ \\
\hline First pregnancy $n(\%)$ & & $17(51.5)$ & $6(54.5)$ & $11(50)$ & $0.805^{\infty}$ \\
\hline \multirow[t]{3}{*}{ Pre-gestational smoker $n(\%)$} & No & $21(63.6)$ & $7(63.6)$ & $14(63.6)$ & $0.710^{\infty}$ \\
\hline & Yes & 7 (21.2) & $3(27.3)$ & $4(18.2)$ & \\
\hline & Former smoker & $5(15.2)$ & $1(9.1)$ & $4(18.2)$ & \\
\hline Pre-gestational tobacco dose (packs/year) & & $2(0-10)$ & $0(0-10)$ & $2.75(0-10)$ & $0.428^{\mathscr{I}}$ \\
\hline Gestational smoker n (\%) & & $4(12.1)$ & $1(9.1)$ & $3(13.6)$ & $0.427^{\infty}$ \\
\hline Neck circumference (cm) & & $33.5 \pm 2.3$ & $34 \pm 1.7$ & $33.3 \pm 2.6$ & $0.403^{¥}$ \\
\hline Waist (cm) & & $100.7 \pm 12$ & $103.9 \pm 5.8$ & $99 \pm 14$ & $0.284^{¥}$ \\
\hline Hip circumference (cm) & & $104.5 \pm 6.9$ & $103.7 \pm 6.2$ & $104.9 \pm 7.6$ & $0.767^{¥}$ \\
\hline Glucose (mg/dL) & & $73.3 \pm 8.5$ & $69.2 \pm 7.9$ & $75.1 \pm 8.3$ & $0.068^{¥}$ \\
\hline Insulin ( $\mu \cup \mathrm{I} / \mathrm{mL})$ & & $10.3(7.6-14.5)$ & $13.3(9.7-15)$ & $9.4(7.5-12.9)$ & $0.108^{\mathbb{I}}$ \\
\hline HOMA-IR & & $1.8(1.3-2.6)$ & $2.6(1.3-3)$ & $1.6(1.3-2.4)$ & $0.327^{\mathbb{I l}}$ \\
\hline Total cholesterol (mg/dL) & & $279 \pm 49$ & $286 \pm 57$ & $274 \pm 46$ & $0.537^{¥}$ \\
\hline Triglycerides (mg/dL) & & $189(163-237)$ & $221(179-279)$ & $179(160-219)$ & $0.122^{\mathbb{q}}$ \\
\hline HDL (mg/dL) & & $72 \pm 13$ & $68 \pm 15$ & $73 \pm 12$ & $0.311^{¥}$ \\
\hline LDL (mg/dL) & & $16 \pm 3$ & $173 \pm 43$ & $166 \pm 433$ & $0.651^{¥}$ \\
\hline $\operatorname{ALT}(\mathrm{U} / \mathrm{L})$ & & $13(10-17)$ & $16(10-28)$ & $13(10-16)$ & $0.338^{\Psi}$ \\
\hline GGT (U/L) & & $9(7-13)$ & $9(8-17)$ & $9(7-12)$ & $0.644^{\pi}$ \\
\hline Hemoglobin (g/dL) & & $11.9 \pm 0.9$ & $11.4 \pm 0.9$ & $12.1 \pm 0.9$ & $0.084^{¥}$ \\
\hline Leucocytes (10³/uL) & & $9.75 \pm 2.16$ & $10.52 \pm 2.25$ & $9.4 \pm 2.08$ & $0.178^{¥}$ \\
\hline Platelets (10³/uL) & & $226.81 \pm 52.39$ & $246.8 \pm 41.68$ & $217.7 \pm 55.05$ & $0.149^{¥}$ \\
\hline Systolic BP (mmHg) & & $105 \pm 9$ & $105 \pm 11$ & $105 \pm 9$ & $0.990^{¥}$ \\
\hline Diastolic BP (mmHg) & & $65 \pm 7$ & $67 \pm 9$ & $64 \pm 6$ & $0.263^{¥}$ \\
\hline
\end{tabular}

Descriptive analysis and comparison between groups. Continuous variables in mean $\pm S D$ if they follow normal distribution or in median (IQR) if they follow a non-parametric distribution. For categorical variables $n$ (\%). Statistical tests, $t$-Student ${ }^{¥}$; U Mann- Whitney"li; Chi-square ${ }^{\infty}$. BMI, body mass index; HOMA-IR, homeostasis model assessment of insulin resistance; HDL, high-density lipoprotein; LDL, low-density lipoprotein; ALT, alanine aminotransferase; GGT, gamma glutamyl-transpeptidase; BP, blood pressure; g, grams; Kg, kilograms; mg, milligrams; $m$, meter; cm, centimeter; $d L$, deciliter; U, units; L, liter, $u L$, microliter; $m m H g$, millimeter of mercury.

between OSA and controls (Table 2). In addition, we did not find differences in specific OSA physical examination.

Cesarean section was performed in $18 \%, 2$ (18.2\%) in OSA group, and $4(18.2 \%)$ in non-OSA pregnant women. The deliveries were instrumented in 21 , and $24 \%$ were induced deliveries; there were no miscarriages. None of them had vaginal candidiasis, pre-eclampsia, or proteinuria, but $7.1 \%$ had urinary infection. There were no significant differences between OSA and non-OSA pregnant women in all these clinical data.

\section{Inflammatory Profile}

Pregnant women with OSA had higher levels of TNF- $\alpha$, IL-1 $\beta$, IL-8, and IL-10 compared to pregnant women without OSA. However, IL-6 was not significantly different (Table 3, Figure 1). Considering that the comparative study based on AHI revealed significant differences in TST, corrected comparisons were made applying a general linear model, and the existing differences in TNF- $\alpha$, and IL-8 retained its statistical significance $(6.91 \pm 0.54$ vs. $5.19 \pm 0.37 \mathrm{pg} / \mathrm{mL}, p=0.016 ; 1.97 \pm 0.24$ vs. $1.17 \pm 0.16$ $\mathrm{pg} / \mathrm{mL}, p=0.012$, respectively), but IL- $1 \beta$ and IL-10 no longer reached statistical significance. Additionally, the study groups were homogeneous in their anthropometric characteristics, corrected comparisons were made adjusted for BMI before pregnancy and gestational age at plasma sampling, and BMI and gestational age at plasma sampling as covariate factors, respectively, and the existing differences in TNF- $\alpha$, and IL- 8 remained its statistical significance (Supplementary Tables 1, 2).

\section{Correlations Between the Inflammatory Profile and Sleep Characteristics}

Significant positive correlations were identified between AHI during REM and TNF- $\alpha(r=0.40, p=0.023)$, IL-6 $(r$ $=0.52, p=0.002)$, IL-8 $(r=0.43, p=0.012)$, and IL$1 \beta(r=0.36, p=0.038)$ concentrations. Significant positive relationships were also found between index, total number, maximum, and mean duration of obstructive apneas and TNF$\alpha(r=0.46, p=0.007 ; r=0.47, p=0.007 ; r=0.42, p$ $=0.017, r=0.45, p=0.008$, respectively). Total number of 
TABLE 2 | Polysomnography data, sleep symptoms, and physical characteristics in OSA and non-OSA groups.

\begin{tabular}{|c|c|c|c|c|c|}
\hline Variables & & Total & OSA $(n=11)$ & Non-OSA $(n=22)$ & $p$-value \\
\hline Total sleep time, (min) & & $306 \pm 66$ & $269 \pm 74$ & $325 \pm 55$ & $0.02^{¥}$ \\
\hline N1 + N2 sleep time (\%) & & $64.1(59.8-72.5)$ & $60.9(20.1-66.1)$ & $66.2(60.7-73.1)$ & $0.127^{\mathbb{I}}$ \\
\hline N3 sleep time (\%) & & $22.1(16.8-27.1)$ & $26.4(16.2-57.2)$ & $19.7(16.9-23.6)$ & $0.127^{\mathbb{I}}$ \\
\hline REM sleep time (\%) & & $11.69 \pm 5.66$ & $11.43 \pm 7.55$ & $11.83 \pm 4.64$ & $0.852^{¥}$ \\
\hline $\mathrm{AHI}\left(\mathrm{h}^{-1}\right)$ & & $0.7(0.2-6)$ & $7.8(5.6-9.7)$ & $0.35(0.07-0.7)$ & $0.001^{\mathbb{I}}$ \\
\hline OAI $\left(h^{-1}\right)$ & & $0(0-0.1)$ & $0.2(0-0.4)$ & $0(0-0)$ & $0.004^{\mathbb{T}}$ \\
\hline Arousal index $\left(\mathrm{h}^{-1}\right)$ & & $9.9(0.25-19.6)$ & $16.10(6.8-19.9)$ & $6.10(0-17.98)$ & $0.098^{\mathbb{T}}$ \\
\hline REM AHI $\left(h^{-1}\right)$ & & $1(0-5.65)$ & $8.4(1.7-23.5)$ & $0(0-1.48)$ & $0.001^{\pi}$ \\
\hline Mean $\mathrm{SpO}_{2}(\%)$ & & $96(95-97)$ & $96(95-97)$ & $96(95-97)$ & $0.546^{\mathbb{I}}$ \\
\hline Minimum $\mathrm{SpO}_{2}(\%)$ & & $92 \pm 2$ & $91 \pm 3$ & $93 \pm 2$ & $0.013^{¥}$ \\
\hline CT90\% $\mathrm{SpO}_{2}$ (min) & & $0(0-0)$ & $0(0-0.1)$ & $0(0-0)$ & $0.08^{\mathbb{q}}$ \\
\hline Desaturation index $\left(\mathrm{h}^{-1}\right)$ & & $0.1(0-0.6)$ & $1.10(0.3-2.3)$ & $0(0-0.15)$ & $0.001^{\mathbb{I}}$ \\
\hline Nocturia $n(\%)$ & & $29(87.9)$ & 9 (81.8) & $20(90.9)$ & $0.407^{\infty}$ \\
\hline Reported apneas, $n$ (\%) & & $2(6.1)$ & $2(18.2)$ & $0(0)$ & $0.104^{\infty}$ \\
\hline Frequent gasping awakenings, $n$ (\%) & & $4(12.1)$ & $3(27.3)$ & $1(4.5)$ & $0.097^{\infty}$ \\
\hline Morning headaches $n$ (\%) & & $4(12.1)$ & $3(27.3)$ & $1(4.5)$ & $0.097^{\infty}$ \\
\hline Unrefreshing sleep $n(\%)$ & & $20(60.6)$ & 7 (63.6) & $13(59.1)$ & $0.801^{\infty}$ \\
\hline Snoring (always/frequent) $n$ (\%) & & $8(25)$ & 3 (27.3) & 5 (23.8) & $0.830^{\infty}$ \\
\hline Reported sleep time, working days (h) & & $7(6-8)$ & $6(4-8)$ & $7(6-8)$ & $0.402^{\mathbb{I}}$ \\
\hline Reported sleep time, weekends (h) & & $7.5(6-8.3)$ & $6(4-8.5)$ & $7.5(7-8)$ & $0.576^{\text {II }}$ \\
\hline Micrognatia n (\%) & & $2(6.1)$ & $0(0)$ & $2(9)$ & $0.542^{\infty}$ \\
\hline \multirow[t]{2}{*}{ Mallampati score n (\%) } & $1-1 \mid$ & $26(81.3)$ & $8(72.7)$ & $18(85.7)$ & $0.390^{\infty}$ \\
\hline & III-IV & $6(18.8)$ & $3(27.3)$ & $3(14.3)$ & \\
\hline Epworth sleepiness scale & & $6.5 \pm 3$ & $6.7 \pm 2.1$ & $6.4 \pm 3.4$ & $0.776^{¥}$ \\
\hline
\end{tabular}

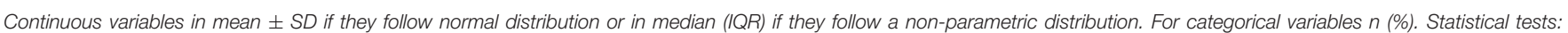

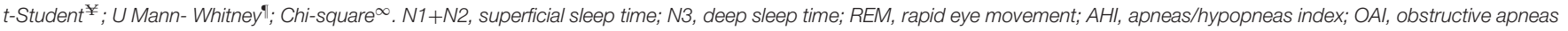
index; $\mathrm{SpO}_{2}$, oxygen saturation; CT90\%, sleep time with oxygen saturation <90\%; min, minutes; $h^{-1}$, per hour; $h$, hours. Values in bold indicate significant difference.

apneas-hypopneas, and AHI were also related to IL-1 $\beta$ values $(r=0.43, p=0.012 ; r=0.43, p=0.012$, respectively $)$ (Figure 2).

We found a mild correlation between CT90\% and IL-8 $(r=0.37, p=0.036)$. No more relationships between nocturnal hypoxemia markers and plasma cytokines were found. Neither recorded TST nor arousal index were significantly associated with cytokine values.

\section{Correlations Between the Inflammatory Profile and Neonatal Characteristics}

Neonatal outcomes are presented in Table 4. None of them had preterm birth (median neonatal gestational age 39.5 (IQR 38-40) weeks), fetal trauma; needed oxygen therapy, phototherapy or were admitted to intensive care units. We did not find significant differences in the neonatal characteristics based on the presence of OSA in pregnant women as shown in Table 4. However, when examining the effects of TNF$\alpha$, and IL-8 on neonatal birth weight, we found significant associations with higher cytokine levels and lower birth weight (Figure 3). A significant inverse significant correlation between IL-8 and neonatal gestational age $(r=-0.48, p=0.007)$ was also found.
TABLE 3 | Inflammatory profiles in pregnant women with and without OSA.

\begin{tabular}{lccc}
\hline Variables & OSA $(\boldsymbol{n}=\mathbf{1 1})$ & Non-OSA $(\boldsymbol{n}=\mathbf{2 2})$ & $\boldsymbol{p}$-value \\
\hline $\mathrm{TNF}-\alpha(\mathrm{pg} / \mathrm{mL})$ & $6.80 \pm 1.39$ & $5.24 \pm 1.77$ & $\mathbf{0 . 0 1 6}$ \\
$\mathrm{IL}-1 \beta(\mathrm{pg} / \mathrm{mL})$ & $0.13(0.10-0.18)$ & $0.09(0.07-0.12)$ & $\mathbf{0 . 0 1 3 ^ { \mathbb { I } }}$ \\
$\mathrm{IL}-6(\mathrm{pg} / \mathrm{mL})$ & $0.97(0.59-1.36)$ & $0.66(0.50-0.74)$ & $0.067^{\mathbb{I}}$ \\
$\mathrm{IL}-8(\mathrm{pg} / \mathrm{mL})$ & $1.62(1.11-2.57)$ & $0.96(0.85-1.53)$ & $\mathbf{0 . 0 1 6 ^ { \mathbb { I } }}$ \\
$\mathrm{IL}-10(\mathrm{pg} / \mathrm{mL})$ & $1.07(0.97-1.20)$ & $0.96(0.86-1.02)$ & $\mathbf{0 . 0 4 3 ^ { \pi }}$
\end{tabular}

Continuous variables in mean $\pm s d$ if they follow normal distribution or in median $(I Q R)$ if they follow a non-parametric distribution. Statistical tests: t-Student ${ }^{¥} ; U$ Mann- Whitney"l; Chi-square ${ }^{\infty}$. TNF- $\alpha$, tumor necrosis factor alpha; IL, interleukin; pg, picograms; $m L$, milliliter. Values in bold indicate significant difference.

\section{DISCUSSION}

Emerging evidence suggests that OSA prevalence increases $(6,7)$ during pregnancy, and it is associated with adverse pregnancyrelated outcomes, such as gestational hypertension, GDM, preeclampsia, preterm birth and low birth weight $(8,11,12,14,29)$. The mechanisms responsible for these associations have not yet been fully elucidated. Among others, it has been proposed that systemic inflammation may play a role as an intermediate 


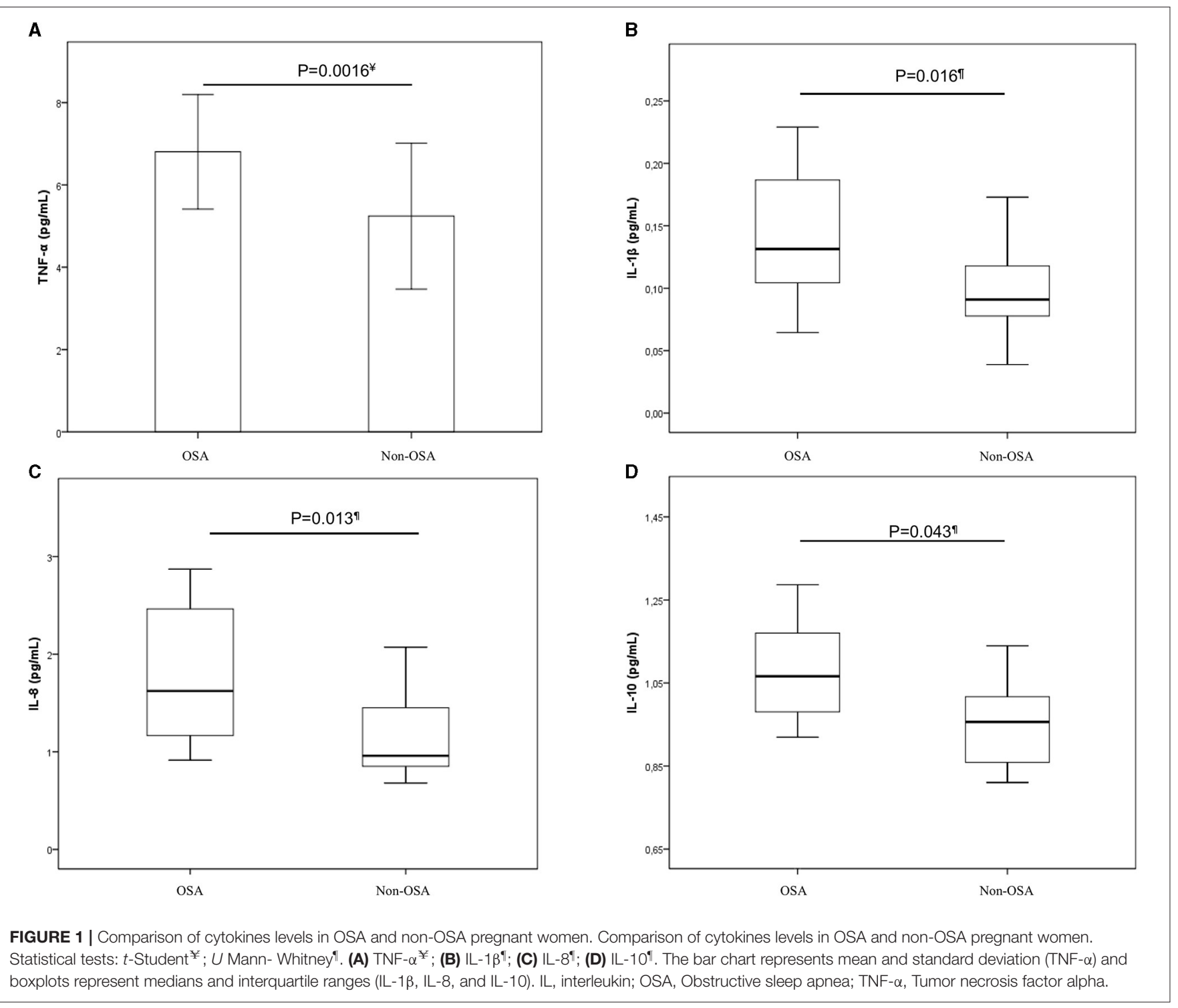

potential mechanism $(30,31)$. However, until now, there were no studies on non-complicated pregnant women with OSA that had specifically investigated the effects on inflammation.

\section{Principal Findings}

Our study provides three main findings of interest. First, women with OSA during pregnancy had significant higher levels of TNF$\alpha$, IL-1 $\beta$, IL-8, and IL-10 compared to women without OSA. Second, there was a significant correlation between systemic inflammation and respiratory obstructive sleep events, especially during REM sleep. Third, systemic inflammation during the third trimester was inversely correlated with neonatal birth weight and newborn gestational age.

\section{Sleep Symptoms in OSA and Non-OSA Groups}

There were no differences in daytime sleepiness and in OSA symptoms between pregnant women with OSA and control subjects. ESS shows low sensitivity and specificity, and it is poorly predictive of OSA during pregnancy $(32,33)$. Reasons that could explain its weakness to identify OSA included the fact that it was designed for a non-pregnant population, and that sleepiness is a common complaint during pregnancy that may be multifactorial and not specific for OSA. Additionally, pregnant women with OSA may not suffer from daytime sleepiness. Similarly, we did not find significant differences in other OSA symptoms, although there was a clear trend in some of them (frequent gasping awakenings, morning headaches) (Table 2). Our study aim was to compare the levels of inflammatory cytokines in pregnant women with and without OSA, and the sample size of the present study may be not sufficiently powered to find differences in the sleep symptoms.

\section{Inflammatory Profile and OSA}

Many studies have shown that OSA in non-pregnant populations increases the concentration of some pro-inflammatory cytokines 

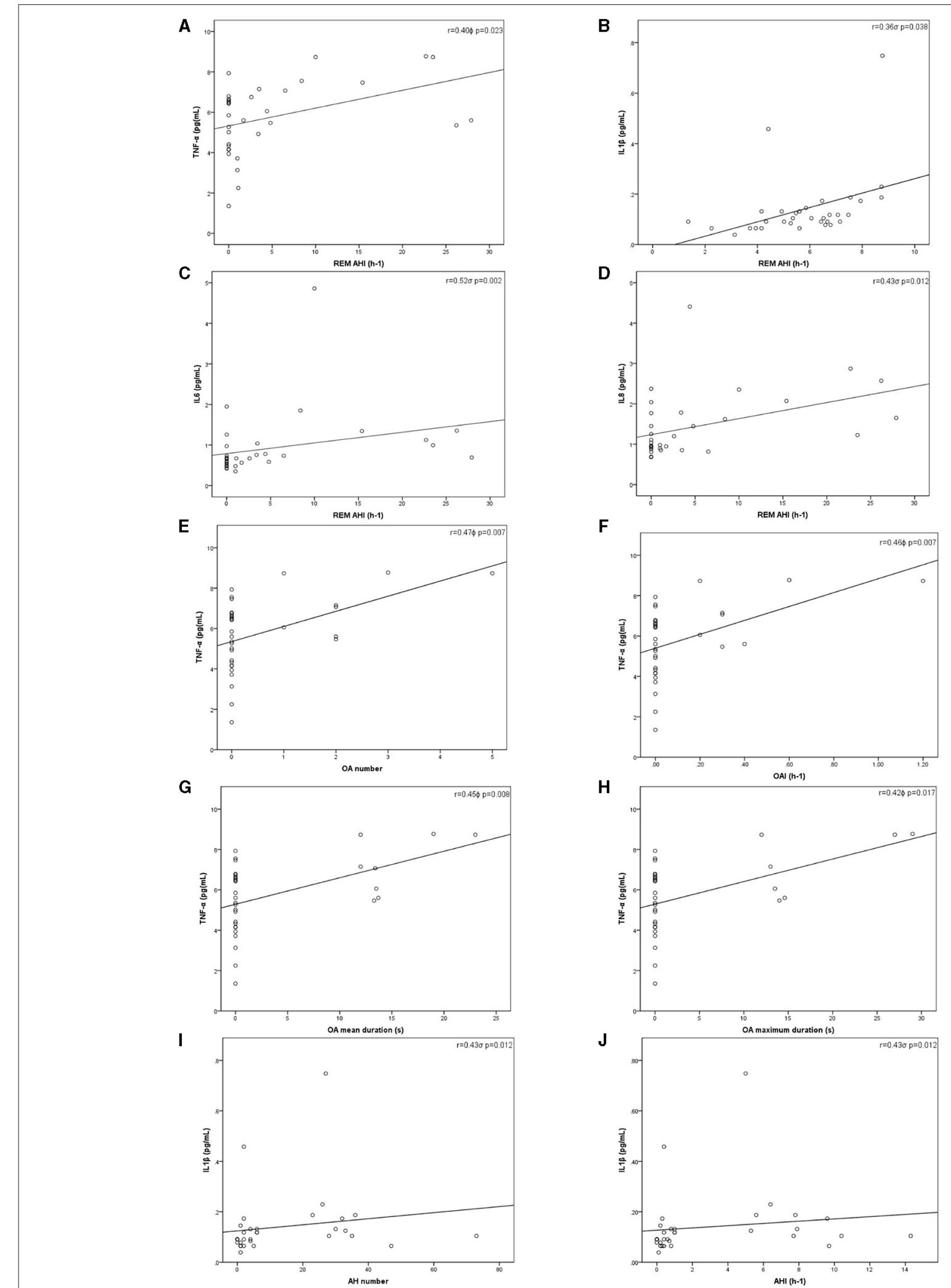

FIGURE 2 | Inflammatory cytokines levels and sleep study parameters correlations. Pearson ${ }^{\phi}$ (TNF- $\alpha$ ) and Rho de Spearman ${ }^{\sigma}$ (IL-1 $1 \beta$, IL-6, IL-8, and IL-10) correlations. (A) Correlation between TNF- $\alpha$ and REM AHI ${ }^{\phi}$; (B) Correlation between IL-1 $\beta$ and REM AHI ${ }^{\sigma}$; (C) Correlation between IL-6 and REM AHI ${ }^{\sigma}$; (D) Correlation between IL-8 and REM AHI ${ }^{\sigma}$; (E) Correlation between TNF- $\alpha$ and the total number of OA ${ }^{\phi}$; (F) Correlation between TNF- $\alpha$ and OAl ${ }^{\phi}$; (G) Correlation

(Continued) 
FIGURE 2 | between TNF- $\alpha$ and mean duration of $\mathrm{OA}^{\phi}$; (H) Correlation between TNF- $\alpha$ and maximum duration of OA ${ }^{\phi}$; (I) Correlation between IL-1 $\beta$ and the total number of $\mathrm{AH}^{\sigma}$; $(\mathbf{J})$ Correlation between IL-1 $\beta$ and $A H^{\sigma}{ }^{\sigma}$. AHI, Apneas-hypopneas index; IL, Interleukin; OA, Obstructive apneas; OAl, Obstructive apneas index; $p$, $p$-value; $r$, Correlation coefficient; REM, Rapid eye movement; TNF- $\alpha$, Tumor necrosis factor alpha.

TABLE 4 | Neonatal characteristics in OSA and non-OSA groups.

\begin{tabular}{|c|c|c|c|c|c|}
\hline Variables & & Total & OSA & Non-OSA & $p$-value \\
\hline Birth weight (Kg) & & $3.21(3.01-3.39)$ & $3.25(2.94-3.62)$ & $3.21(3.09-3.39)$ & $0.963^{\pi}$ \\
\hline Birth weight (percentile) & & $51.2 \pm 23$ & $51.9 \pm 29.8$ & $50.9 \pm 20.9$ & $0.870^{¥}$ \\
\hline Head circumference (cm) & & $35(34-36)$ & $34(33-34)$ & 35 (34-36) & $0.215^{\pi}$ \\
\hline Umbilical cord pH & & $7.30 \pm 0.07$ & $7.30 \pm 0.05$ & $7.29 \pm 0.07$ & $0.739^{¥}$ \\
\hline \multirow[t]{2}{*}{ Gender $n(\%)$} & M & $14(46.7)$ & $4(50)$ & $10(45.5)$ & $1.000^{\infty}$ \\
\hline & $\mathrm{F}$ & $16(53.3)$ & $4(50)$ & $12(54.5)$ & \\
\hline Neonatal gestational age (weeks) & & $39.5(38-40)$ & $39(39-39.8)$ & $40(38-40.3)$ & $0.383^{\mathbb{T}}$ \\
\hline
\end{tabular}

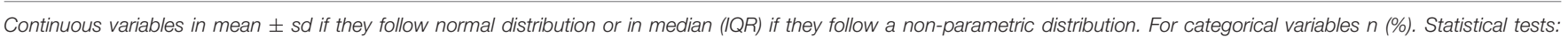
t-Student ${ }^{¥}$; U Mann-Whitney ${ }^{\mathbb{I l}}$; Chi-square ${ }^{\infty}$. M, male; F, female; Kg, kilogram; cm, centimeter; min, minutes.

such as TNF- $\alpha$, IL-1 $\beta$, IL-6, and IL-8, among others (34-37). However, there are contradictory results that may be due to significant influence of age, weight, gene polymorphisms, or lifestyle. Similarly, there are conflicting data in IL-10 levels. Some studies found that they are lower in OSA (38) while others conclude that there were no significant differences between OSA and healthy patients (34). The third trimester of pregnancy is characterized by a low grade inflammation, which is necessary for the correct evolution throughout pregnancy (16). Specifically, both the levels of pro-inflammatory cytokines such as IL-1 $\beta$, IL-6, and IL-8 (15-17) as well as anti-inflammatories such as IL-10 (39) increase during healthy pregnancy. However, there are many discrepancies in the previous studies and even in the quantified values, which change within the trimesters of gestation, comorbidities, obesity, percentage of visceral adipose tissue, and treatments. Besides, the variation coefficients of the different techniques used, most of them by means of enzyme immunoassays in solid phase, as they are semi-automated and with high inaccuracies, can originate different measurements among the reported studies. It is important to point out that there is not an international standardization in the techniques to report harmonized results either. However, some other groups reported similar cytokine concentrations to our study values (19, 39-46). In the present study there were no differences in age or BMI, which set aside important confounders, such as maternal age and obesity when evaluating inflammation. We found that OSA pregnant women presented higher values of TNF- $\alpha$, IL- $1 \beta$, IL8 , and IL-10 cytokines compared to non-OSA ones. Moreover, there were significant and positive relationships between some inflammatory markers and the number of obstructive respiratory events per hour during sleep. As far as we know, this is the first description on the influence of repetitive nocturnal obstructive apneas events in systemic inflammation in non-complicated pregnant women.
Interestingly, we found significant positive correlations between AHI during REM and TNF- $\alpha$, IL-6, IL-8, and IL-1 $\beta$. REM sleep accounts for around $25 \%$ of total sleep time in healthy adults. OSA isolated to REM sleep in general population has been independently associated with prevalent and incident hypertension, as well as with insulin resistance $(47,48)$. OSA events during REM sleep are usually longer than those during non-REM sleep and are often followed by more pronounced hypoxemia, consequently they could be more harmful. In addition, REM sleep is associated with intensified sympathetic activation, which may further upgrade negative physiologic responses. OSA in REM prevalence ranges between 10 and 36\%, being more frequent in women, younger individuals and those with mild to moderate OSA (49). We speculate that REM-OSA during pregnancy may lead to upregulation of the inflammatory response, which might intensify the risk of worse maternal-fetal outcomes. Nonetheless, future studies are required to further explore the role of REM-OSA and these inflammatory markers during pregnancy as well as their influence in hypothetical human gestation complications.

We found a mild correlation between CT90\% and IL8. No more significant relationships between nocturnal hypoxemia indexes and plasma cytokines were found. Consequently, pregnancy inflammation response to OSA may be more susceptible to respiratory obstructive sleep events, especially during REM sleep rather than to during nocturnal hypoxemia. However, studies to a greater extent are needed to better determine the influence of nocturnal hypoxemia on systemic inflammation, given that women of the present study presented very mild impact of OSA on nocturnal hypoxemia indexes, limiting any other further analysis (Table 2).

TST (objectively measured by PSG) was significantly shorter in the OSA group. Nevertheless, there was no clear external cause 


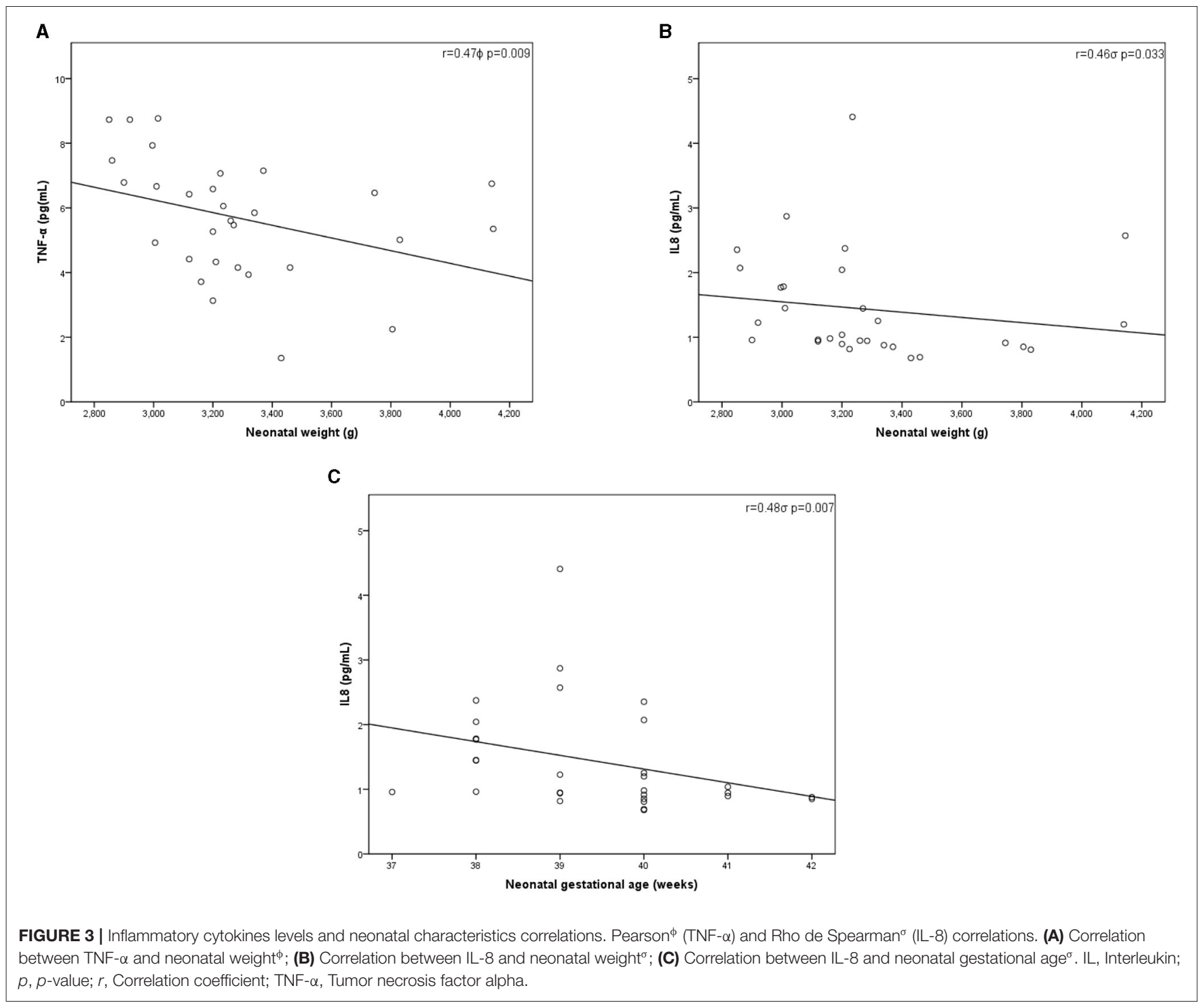

for worsened sleep quality in the OSA group, and significant differences in subjective self-reported sleep time were not found either. Corrected comparisons were made applying a general linear model. TNF- $\alpha$, and IL- 8 remained higher in the OSA group compared to women with $\mathrm{AH}<5 \mathrm{~h}^{-1}$, but IL-1 $\beta$ and IL-10 no longer reached statistical significance. However, neither TST nor arousal index were significantly associated with cytokine values. Other studies found that women with GDM or gestational hypertension had markedly lower TST, and a higher AHI (with higher proportion of OSA) than women with uncomplicated pregnancies $(50,51)$. Similarly, a study of 234 pregnant women showed a trend toward decreased TST as the severity of AHI categories increased (52). We hypothesize that the short TST of the OSA women may have been a consequence of OSA-induced sleep disruption, and one of the intermediate mechanisms that may lead OSA to increase inflammation during pregnancy.

\section{Inflammatory Profile and Pregnancy and Neonatal Outcomes}

Some inflammatory cytokines, such as IL-1 $\beta$, IL-6, IL-8, and TNF- $\alpha$, have been implicated in the pathogenesis of pregnancy complications such as pre-eclampsia and GDM (18-21). Similarly to us, Bublitz et al. showed higher levels of IL-6, IL-8, and TNF- $\alpha$ in a small group of women with GDM with OSA compared to women without OSA (53). Nevertheless, the findings of the latter study should be interpreted cautiously since, despite there were no differences in BMI, they included only 4 women with OSA with mean BMI of 36.4. Moreover, OSA status was diagnosed at home with a type III portable device, which has not been validated in pregnant women.

IL-10 is an immunosuppressive cytokine that plays an important role in controlling the equilibrium of pro- and antiinflammatory response, essential for pregnancy maintenance and 
development, as well as for placental growth and remodeling for a successful pregnancy (40). Our results showed higher levels of IL10 in pregnant women with OSA compared to control subjects. Although there are conflicting studies, in the same way, many authors found that complicated pregnancies presented higher serum levels of IL-10 than healthy women (21).

In the present study we included mild OSA women (AHI median $7.8 \mathrm{~h}^{-1}$ ), which, however represent the typical range of OSA during pregnancy (8). Few studies have investigated the consequences of mild maternal OSA. Recent studies, in which OSA cases were mostly mild, found that even modest elevations of AHI were associated with an increased risk of hypertensive disorders and GDM $(8,50)$. Nonetheless, other studies showed contradictory results on the effects of mild OSA in a composite of adverse pregnancy outcomes (54), or in the GDM/pre-eclampsia risk (55). Birth weight is a critical fetal outcome, and a surrogate indicator of the intrauterine environment. The relationship between objective measures of mild OSA and birth weight has been hardly studied with mixed results and remains currently unclear. Some studies suggest that maternal OSA in pregnancy (even in a mild form) is associated with reduced fetal growth in late pregnancy (14), and with an increased risk of delivering a small-for-gestationalage infant (52), while other studies showed contrasting findings (56-58). Such inconsistencies may relate to differences in sample characteristics with heterogeneous populations, with inadequate control on confounders, such as pre-gestational BMI and pregnancy complications, and methodological differences in terms of sleep assessment procedures, as well as timing of sleep evaluation. As pregnancy is associated with mostly mild OSA, further study is warranted in these patients to better understand the mechanisms and consequences of OSA in this unique population.

Our study supports previous findings that showed an association of maternal cytokines (IL-8 and TNF- $\alpha$ ) with perinatal complications $(20,22,59)$. We showed a moderate correlation with lower neonatal birth weight and maternal IL- 8 and TNF- $\alpha 1$ levels. In the same way, maternal TNF$\alpha$ concentration was inversely associated with birth weight in normal weight women (60). Human and animal studies also found that higher maternal plasma TNF- $\alpha$ concentration was associated with smaller birth weights (22, 61-63). However, there are conflicting results, as other studies did not find correlations with either birth weight or fetal growth restriction $(64,65)$. There is a heterogeneous inflammatory profile which may be related to the timing of pregnancy in when the samples were collected, the complexity in interpreting dynamic cytokine profiles, differences in assay methodologies, gene polymorphism or comorbidities, as well as diet and lifestyle among others (66). Our study aim was to compare the levels of inflammatory cytokines in pregnant women with and without OSA. Thus, the sample size of the present study may be not sufficiently powered to find differences in maternal and perinatal outcomes. Likewise, the median observed birth weight was 3,210 g, and none of the subjects met the criteria for low birth weight, which could limit further analysis to study. While we did not find significant differences in perinatal outcomes between OSA and non-OSA groups, we did find correlates of OSA and proinflammatory cytokines. It is plausible that maternal systemic inflammation related to OSA, although very mild, may disturb growth pattern of the offspring. It is however unlikely that a single mechanistic pathway could modify birth weight. Increments in oxidative stress, and in sympathetic activation, modifications in the angiogenic balance, and endothelial dysfunction may all play a role. Notwithstanding such considerations, the impact of OSA during pregnancy on fetal outcomes and whether OSArelated inflammation could be one intermediate mechanism have yet to be determined with further studies presenting a larger sample size.

\section{Strengths and Limitations}

The present study has several strengths, such as novelty, a multi-center approach, prospective enrolment, careful selection of patients and controls in which comorbidities were carefully excluded, who were homogeneous in age and body mass index (BMI), and intensive sleep and clinical phenotyping, including the performance of attended PSG. Additionally, the laboratory researchers were blinded to maternal status. Yet, as in any study, there are some potential limitations that deserve to be commented on. First, the sample size was relatively small. This was due to the difficulty of including pregnant women with newly diagnosed OSA, but otherwise healthy (prevalence is around 10\%) (8). Despite this fact, the number of individuals included was sufficiently powered to observe significant differences. Second, since our study included mainly Caucasian women, our results may not be directly applicable to other ethnic groups. Third, since episodes of flow limitation $<30 \%$ associated with arousal were not scored, we cannot ascertain whether our results would still be similar.

\section{CONCLUSIONS}

To conclude, we have found that pregnant women with OSA without comorbidities had higher systemic inflammation than healthy pregnant women without OSA, which was related to respiratory obstructive sleep events, especially during REM. In addition, the existence of systemic inflammation in pregnancy was inversely correlated with the newborn weight and age. Future studies are needed to further explore the hypothesis that increments in OSA-related maternal systemic inflammation could be an intermediate mechanism linking OSA during pregnancy and adverse maternal and perinatal outcomes, such as GDM, pre-eclampsia, or fetal birthweight (20). Furthermore, the influence and possible correlation of maternal inflammation on the fetal inflammation markers still needs to be tested. Lastly, additional data regarding the progression of the inflammatory profile of pregnant women after delivery, as well as the potential influence if the OSA condition during pregnancy is corrected, are needed to better assess the risk of OSA-related systemic inflammation during pregnancy. 


\section{DATA AVAILABILITY STATEMENT}

Data cannot be made publicly available for ethical reasons as study participants did not give consent for public data sharing: due to the ethical restrictions related to the consent of the participants of the public deposition of the data, as well as legal limitations of the Spanish legislation on data protection, it is not possible to have the permissions to publically access the database. However, other researchers who meet the criteria for access to confidential data, may request to gain access to the minimal data set underlying the results under request at the Ethics Committee (ceic_ib@caib.es), which will evaluate the data request proposal within the meaning of Medical Research involving Human Subjects.

\section{ETHICS STATEMENT}

The studies involving human participants were reviewed and approved by Comité de Ética de La Investigación de Las Islas Baleares (CEI-IB). The patients/participants provided their written informed consent to participate in this study.

\section{AUTHOR CONTRIBUTIONS}

AA-F, JS, and FG-R conceived and designed the study, contributed to data interpretation, and writing the manuscript.

\section{REFERENCES}

1. Peppard PE, Young T, Barnet JH, Palta M, Hagen EW, Hla KM. Increased prevalence of sleep-disordered breathing in adults. Am J Epidemiol. (2013) 177:1006-14. doi: 10.1093/aje/Kws342

2. Ryan S. Adipose Tissue inflammation by intermittent hypoxia: mechanistic link between obstructive sleep apnoea and metabolic dysfunction. J Physiol. (2017) 595:2423-30. doi: 10.1113/JP273312

3. Arias MA, García-Río F, Alonso-Fernández A, Hernanz A, Hidalgo $\mathrm{R}$, Martínez-Mateo $\mathrm{V}$, et al. Decreases plasma levels of soluble tumour necrosis factor-alpha receptor 1 in obstructive sleep apnoea. Eur Respir J. (2008) 32:1009-15. doi: 10.1183/09031936.000 07008

4. Sozer V, Kutnu M, Atahan E, Caliskaner Ozturk B, Hysi E, Cabuk C, et al. Changes in inflammatory mediators as a result of intermittent hypoxia in obstructive sleep apnea syndrome. Clin Respir J. (2018) 12:161522. doi: $10.1111 /$ crj. 12718

5. Wang SH, Keenan BT, Wiemken A, Zang Y, Staley B, Sarwer DB, et al. Effect of weight loss on upper airway anatomy and the apnea hypopnea index: the importance of tongue fat. Am J Respir Crit Care Med. (2020) 201:1-54. doi: 10.1164/Rccm.201903-0692OC

6. Dominguez JE, Street L, Louis J, Dominguez J. Management of obstructive sleep apnea in pregnancy. Obstet Gynecol Clin North Am. (2018) 45:23347. doi: 10.1016/j.ogc.2018.01.001

7. Izci B, Riha RL, Martin SE, Vennelle M, Liston WA, Dundas KC, et al. The upper airway in pregnancy and pre-eclampsia. Am J Respir Crit Care Med. (2003) 167:137-40. doi: 10.1164/Rccm.200206-590OC

8. Facco FL, Parker CB, Reddy UM, Silver RM, Koch MA, Louis JM, et al. Association between sleep-disordered breathing and hypertensive disorders of pregnancy and gestational diabetes mellitus. Obstet Gynecol. (2017) 129:3141. doi: 10.1097/AOG.0000000000001805

9. Zhang X, Zhang R, Cheng L, Wang Y, Ding X, Fu J, et al. The effect of sleep impairment on gestational diabetes mellitus: a systematic
MCe, AA, AS, MCo, PR, CR, AH, MG, CP, AG, MB, MD, $\mathrm{AB}, \mathrm{DM}-\mathrm{G}, \mathrm{AI}, \mathrm{JD}, \mathrm{JP}, \mathrm{JC}$, and JM contributed to literature search, to recruit patients, to data analysis and interpretation, and writing the manuscript. All authors contributed to the article and approved the submitted version.

\section{FUNDING}

This research was partially supported by grants from SEPAR2010-820, Ministerio de Economía y Competitividad (PI10/00495) and Ministerio de Ciencia, Innovación y Universidades (PI19/00875).

\section{ACKNOWLEDGMENTS}

We thank all the pregnant women for their willingness to participate in the study. Besides, the authors thank Meritxell Arqué, for her assistance in the fieldwork of the study, and Juan G. Rebolo Roca and M. M. Amengual Salas for their language assistance.

\section{SUPPLEMENTARY MATERIAL}

The Supplementary Material for this article can be found online at: https://www.frontiersin.org/articles/10.3389/fmed. 2021.674997/full\#supplementary-material

review and meta-analysis of cohort studies. Sleep Med. (2020) 74:26777. doi: 10.1016/j.Sleep.2020.05.014

10. Wanitcharoenkul E, Chirakalwasan N, Amnakkittikul S, Charoensri S, Saetung S, Chanprasertyothin S, et al. Obstructive sleep apnea and diet-controlled gestational diabetes. Sleep Med. (2017) 39:101-7. doi: 10.1016/j.Sleep.2017.08.010

11. Champagne K, Schwartzman K, Opatrny L, Barriga P, Morin L, Mallozzi A, et al. Obstructive sleep apnoea and its association with gestational hypertension. Eur Respir J. (2009) 33:55965. doi: $10.1183 / 09031936.00122607$

12. Pamidi S, Pinto LM, Marc I, Benedetti A, Schwartzman K, Kimoff RJ. Maternal sleep-disordered breathing and adverse pregnancy outcomes: a systematic review and metaanalysis. Am J Obstet Gynecol. (2014) 210:52.e1e14. doi: 10.1016/j.Ajog.2013.07.033

13. Warland J, Dorrian J, Morrison JL, O'Brien LM. Maternal sleep during pregnancy and poor fetal outcomes: a scoping review of the literature with meta-analysis. Sleep Med Rev. (2018) 41:197-219. doi: 10.1016/j.Smrv.2018.03.004

14. Fung AM, Wilson DL, Lappas $M$, Howard $M$, Barnes $M$, O'Donoghue F, et al. Effects of maternal obstructive sleep apnoea on fetal growth: a prospective cohort study. PLoS ONE. (2013) 8:e0068057. doi: 10.1371/Journal.Pone.0068057

15. Mor G, Cardenas I, Abrahams V, Guller S. Inflammation and pregnancy: the role of the immune system at the implantation site. Ann N Y Acad Sci. (2011) 1221:80-7. doi: 10.1111/j.1749-6632.2010.05938.x

16. Nadeau-Vallée M, Obari D, Palacios J, Brien M-Ė, Duval C, Chemtob S, et al. Sterile inflammation and pregnancy complications: a review. Reproduction. (2016) 152:R277-92. doi: 10.1530/REP-16-0453

17. Orsi NM, Tribe RM. Cytokine networks and the regulation of uterine function in pregnancy and parturition. J Neuroendocrinol. (2008) 20:4629. doi: $10.1111 /$ j.1365-2826.2008.01668.x

18. Atègbo J-M, Grissa O, Yessoufou A, Hichami A, Dramane KL, Moutairou K, et al. Modulation of adipokines and cytokines in 
gestational diabetes and macrosomia. J Clin Endocrinol Metab. (2006) 91:4137-43. doi: 10.1210/jc.2006-0980

19. Ferguson KK, Meeker JD, McElrath TF, Mukherjee B, Cantonwine DE. Repeated measures of inflammation and oxidative stress biomarkers in preeclamptic and normotensive pregnancies. Am J Obstet Gynecol. (2017) 216:527.e1-e9. doi: 10.1016/j.Ajog.2016.12.174

20. Guven MA, Coskun A, Ertas IE, Aral M, Zencirci B, Oksuz H. Association of maternal serum CRP, IL-6, TNF-Alpha, homocysteine, folic acid and vitamin B12 levels with the severity of preeclampsia and fetal birth weight. Hypertension Pregnancy. (2009) 28:190-200. doi: 10.1080/10641950802601179

21. Szarka A, Rigó J, Lázár L, Beko G, Molvarec A. Circulating cytokines, chemokines and adhesion molecules in normal pregnancy and preeclampsia determined by multiplex suspension array. BMC Immunol. (2010) 11:59. doi: 10.1186/1471-2172-11-59

22. Amarilyo G, Oren A, Mimouni FB, Ochshorn Y, Deutsch V, Mandel D. Increased cord serum inflammatory markers in small-for-gestational-age neonates. J Perinatol. (2011) 31:30-2. doi: 10.1038/jp.2010.53

23. Liu L, Su G, Wang S, Zhu B. The prevalence of obstructive sleep apnea and its association with pregnancy-related health outcomes: a systematic review and meta-analysis. Sleep Breath. (2019) 23:399-412. doi: 10.1007/S11325-018-1714-7

24. Winkler G, Cseh K, Baranyi E, Melczer Z, Speer G, Hajós P, et al. Tumor necrosis factor system in insulin resistance in gestational diabetes. Diabetes Res Clin Pract. (2002) 56:93-9. doi: 10.1016/S0168-8227(01)00355-2

25. Chiner E, Arriero JM, Signes-Costa J, Marco J, Fuentes I. Validation of the Spanish version of the epworth sleepiness scale in patients with a sleep apnea syndrome. Archiv Bronconeumol. (1999) 35:4227. doi: 10.1016/S0300-2896(15)30037-5

26. Iber C, Ancoli-Israel S, Chesson AL, Quan SF. The AASM Manual for the Scoring of Sleep and Associated Events: Rules, Terminology and Technical Specifications. Westchester, IL: The American Academy of Sleep Medicine (2007).

27. Berry RB, Budhiraja R, Gottlieb DJ, Gozal D, Iber C, Kapur VK, et al. Rules for scoring respiratory events in sleep: update of the 2007 AASM manual for the scoring of sleep and associated events. Deliberations of the sleep apnea definitions task force of the American Academy of Sleep Medicine. J Clin Sleep Med. (2012) 8:597-619. doi: 10.5664/Jcsm.2172

28. Matthews DR, Hosker JP, Rudenski AS, Naylor BA, Treacher DF, Turner RC. Homeostasis model assessment: insulin resistance and $\beta$-cell function from fasting plasma glucose and insulin concentrations in man. Diabetologia. (1985) 28:412-9. doi: 10.1007/BF00280883

29. Truong KK, Guilleminault C. Sleep disordered breathing in pregnant women: maternal and fetal risk, treatment considerations, and future perspectives. Expert Rev Respir Med. (2018) 12:17789. doi: $10.1080 / 17476348.2018 .1432355$

30. Dominguez JE, Habib AS, Krystal AD, A. Review of the associations between obstructive sleep apnea and hypertensive disorders of pregnancy and possible mechanisms of disease. Sleep Med Rev. (2018) 42:3746. doi: 10.1016/j.Smrv.2018.05.004

31. Gooley JJ, Mohapatra L, Twan DCK. The role of sleep duration and sleep disordered breathing in gestational diabetes mellitus. Neurobiol Sleep Circ Rhythms. (2018) 4:34-43. doi: 10.1016/j.Nbscr.2017.11.001

32. Izci-Balserak B, Zhu B, Gurubhagavatula I, Keenan BT, Pien GW. A screening algorithm for obstructive sleep apnea in pregnancy. Ann Am Thorac Soc. (2019) 16:1286-94. doi: 10.1513/AnnalsATS.201902-131OC

33. Facco FL, Ouyang DW, Zee PC, Grobman WA. Development of a pregnancyspecific screening tool for sleep apnea. J Clin Sleep Med. (2012) 8:38994. doi: 10.5664/Jcsm.2030

34. Cizza G, Piaggi P, Lucassen EA, de Jonge L, Walter M, Mattingly MS, et al. Obstructive sleep apnea is a predictor of abnormal glucose metabolism in chronically sleep deprived obese adults. PLoS ONE. (2013) 8:e65400. doi: 10.1371/Journal.Pone.0065400

35. de Lima FFF, Mazzotti DR, Tufik S, Bittencourt L. The role inflammatory response genes in obstructive sleep apnea syndrome: a review. Sleep Breath. (2016) 20:331-8. doi: 10.1007/S11325-015-1226-7

36. Ming H, Tian A, Liu B, Hu Y, Liu C, Chen R, et al. Inflammatory cytokines tumor necrosis factor- $\alpha$, interleukin- 8 and sleep monitoring in patients with obstructive sleep apnea syndrome. Exp Ther Med. (2018) 17:176670. doi: 10.3892/etm.2018.7110

37. Martínez-Cerón E, Barquiel B, Bezos A-M, Casitas R, Galera R, GarcíaBenito C, et al. Effect of continuous positive airway pressure on glycemic control in patients with obstructive sleep apnea and type 2 diabetes. A randomized clinical trial. Am J Resp Crit Care Med. (2016) 194:47685. doi: 10.1164/Rccm.201510-1942OC

38. Jiang H, Cao H, Wang P, Liu W, Cao F, Chen J. Tumour necrosis factora/interleukin-10 ratio in patients with obstructive sleep apnoea hypopnoea syndrome. J Laryngol Otol. (2015) 129:73-8. doi: 10.1017/S0022215114002990

39. Okun ML, Coussons-Read ME. Sleep disruption during pregnancy: how does it influence serum cytokines? J Reprod Immunol. (2007) 73:15865. doi: 10.1016/j.jri.2006.06.006

40. Holmes VA, Wallace JMW, Gilmore WS, McFaul P, Alexander HD Plasma levels of the immunomodulatory cytokine interleukin-10 during normal human pregnancy: a longitudinal study. Cytokine. (2003) 21:2659. doi: 10.1016/S1043-4666(03)00097-8

41. Moreli JB, Corrêa-Silva S, Damasceno DC, Sinzato YK, LorenzonOjea AR, Borbely AU, et al. Changes in the TNF-Alpha/IL-10 ratio in hyperglycemia-associated pregnancies. Diabetes Res Clin Pract. (2015) 107:362-9. doi: 10.1016/j.Diabres.2015.01.005

42. Brien M-E, Boufaied I, Bernard N, Forest J-C, Giguere Y, Girard S. Specific inflammatory profile in each pregnancy complication: a comparative study. Am J Reprod Immunol. (2020) 84:e13316. doi: 10.1111/aji. 13316

43. Ragsdale HB, Kuzawa CW, Borja JB, Avila JL, McDade TW. Regulation of inflammation during gestation and birth outcomes: inflammatory cytokine balance predicts birth weight and length. Am J Hum Biol. (2019) 31:e23245. doi: 10.1002/Ajhb.23245

44. Stokkeland LMT, Giskeødegård GF, Stridsklev S, Ryan L, Steinkjer B, Tangerås LH, et al. Serum cytokine patterns in first half of pregnancy. Cytokine. (2019) 119:188-96. doi: 10.1016/j.Cyto.2019.03.013

45. Loukovaara S, Immonen I, Koistinen R, Hiilesmaa V, Kaaja R. Inflammatory markers and retinopathy in pregnancies complicated with type I diabetes. Eye. (2005) 19:422-30. doi: 10.1038/sj.eye.6701499

46. Kronborg CS, Gjedsted J, Vittinghus E, Hansen TK, Allen J, Knudsen UB. Longitudinal measurement of cytokines in pre-eclamptic and normotensive pregnancies. Acta Obstet Gynecol Scand. (2011) 90:791-6. doi: 10.1111/j.1600-0412.2011.01134.x

47. Mokhlesi B, Finn LA, Hagen EW, Young T, Hla KM, Van Cauter E, et al Obstructive sleep apnea during REM sleep and hypertension. Results of the Wisconsin sleep cohort. Am J Respir Crit Care Med. (2014) 190:115867. doi: 10.1164/Rccm.201406-1136OC

48. Appleton SL, Vakulin A, Martin SA, Lang CJ, Wittert GA, Taylor AW, et al. Hypertension is associated with undiagnosed OSA during rapid eye movement sleep. Chest. (2016) 150:495-505. doi: 10.1016/j.Chest.2016. 03.010

49. Conwell W, Patel B, Doeing D, Pamidi S, Knutson KL, Ghods F, et al. Prevalence, clinical features, and CPAP adherence in REM-related sleep-disordered breathing: a cross-sectional analysis of a large clinical population. Sleep Breath. (2012) 16:519-26. doi: 10.1007/S11325-0110537-6

50. Izci Balserak B, Pien GW, Prasad B, Mastrogiannis D, Park C, Quinn LT, et al. Obstructive sleep apnea is associated with newlydiagnosed gestational diabetes mellitus. Ann Am Thorac Soc. (2020) 17:754-61. doi: 10.1513/AnnalsATS.201906-473OC

51. Reid J, Skomro R, Cotton D, Ward H, Olatunbosun F, Gjevre J, et al. Pregnant women with gestational hypertension may have a high frequency of sleep disordered breathing. Sleep. (2011) 34:1033-8. doi: 10.5665/SLEE P.1156

52. Pamidi S, Marc I, Simoneau G, Lavigne L, Olha A, Benedetti A, et al. Maternal sleep-disordered breathing and the risk of delivering small for gestational age infants: a prospective cohort study. Thorax. (2016) 71:71925. doi: 10.1136/Thoraxjnl-2015-208038

53. Bublitz MH, Carpenter M, Amin S, Okun ML, Millman R, De La Monte $\mathrm{SM}$, et al. The role of inflammation in the association between gestational diabetes and obstructive sleep apnea: a pilot study. Obstet Med. (2018) 11:18691. doi: $10.1177 / 1753495 \times 18780095$ 
54. Facco FL, Liu CS, Cabello AA, Kick A, Grobman WA, Zee PC. Sleepdisordered breathing: a risk factor for adverse pregnancy outcomes? Am J Perinatol. (2012) 29:277-82. doi: 10.1055/s-0031-1295658

55. Facco FL, Ouyang DW, Zee PC, Strohl AE, Gonzalez AB, Lim C, et al. Implications of sleep-disordered breathing in pregnancy. Am J Obstet Gynecol. (2014) 210:559.e1-6. doi: 10.1016/j.Ajog.2013.12.035

56. Hawkins M, Parker CB, Redline S, Larkin JC, Zee PP, Grobman WA, et al. Objectively assessed sleep-disordered breathing during pregnancy and infant birthweight. Sleep Med. (2021) 81:312-8. doi: 10.1016/j.Sleep.2021. 02.043

57. Wilson DL, Howard ME, Fung AM, O’Donoghue FJ, Barnes M, Lappas $\mathrm{M}$, et al. The presence of coexisting sleep-disordered breathing among women with hypertensive disorders of pregnancy does not worsen perinatal outcome. PLoS ONE. (2020) 15:e0229568. doi: 10.1371/Journal.Pone. 0229568

58. Telerant A, Dunietz GL, Many A, Tauman R. Mild maternal obstructive sleep apnea in non-obese pregnant women and accelerated fetal growth. Sci Rep. (2018) 8:10768. doi: 10.1038/S41598-018-29052-Y

59. Coussons-Read ME, Lobel M, Carey JC, Kreither MO, D’Anna K, Argys $\mathrm{L}$, et al. The occurrence of preterm delivery is linked to pregnancy-specific distress and elevated inflammatory markers across gestation. Brain Behav Immun. (2012) 26:650-9. doi: 10.1016/j.bbi.2012.02.009

60. Perichart-Perera O, Muñoz-Manrique C, Reyes-López A, Tolentino-Dolores M, Espino Y, Sosa S, et al. Metabolic markers during pregnancy and their association with maternal and newborn weight status. PLoS ONE. (2017) 12:e0180874. doi: 10.1371/Journal.Pone.0180874

61. Schipper E-JI, Bolte AC, Schalkwijk CG, Van Geijn HP, Dekker GA. TNF-receptor levels in preeclampsia-results of a longitudinal study in high-risk women. J Matern Fetal Neonatal Med. (2005) 18:2837. doi: 10.1080/14767050500246466

62. Laskowska M, Leszczyńska-Gorzelak B, Laskowska K, Oleszczuk J. Evaluation of maternal and umbilical serum TNFalpha levels in preeclamptic pregnancies in the intrauterine normal and growth-restricted fetus. J Matern Fetal Neonatal Med. (2006) 19:347-51. doi: 10.1080/14767050600637937

63. Posont RJ, Cadaret CN, Beard JK, Swanson RM, Gibbs RL, Marks-Nelson ES, et al. Maternofetal inflammation induced for 2 wk in late gestation reduced birth weight and impaired neonatal growth and skeletal muscle glucose metabolism in lambs. J Anim Sci. (2021) 99:102. doi: 10.1093/jas/ Skab102

64. Farah N, Hogan AE, O'Connor N, Kennelly MM, O'Shea D, Turner MJ. Correlation between maternal inflammatory markers and fetomaternal adiposity. Cytokine. (2012) 60:96-9. doi: 10.1016/j.Cyto.2012.05.024

65. Hahn-Zoric M, Hagberg $\mathrm{H}$, Kjellmer I, Ellis J, Wennergren M, Hanson LA. Aberrations in placental cytokine mRNA related to intrauterine growth retardation. Pediatr Res. (2002) 51:201-6. doi: 10.1203/00006450-200202000-00013

66. Mullins E, Prior T, Roberts I, Kumar S. Changes in the maternal cytokine profile in pregnancies complicated by fetal growth restriction. Am J Reprod Immunol. (2012) 68:1-7. doi: 10.1111/j.1600-0897.2012.01132.x

Conflict of Interest: The authors declare that the research was conducted in the absence of any commercial or financial relationships that could be construed as a potential conflict of interest.

Publisher's Note: All claims expressed in this article are solely those of the authors and do not necessarily represent those of their affiliated organizations, or those of the publisher, the editors and the reviewers. Any product that may be evaluated in this article, or claim that may be made by its manufacturer, is not guaranteed or endorsed by the publisher.

Copyright (C) 2021 Alonso-Fernández, Ribot Quetglas, Herranz Mochales, Álvarez Ruiz De Larrinaga, Sánchez Barón, Rodríguez Rodríguez, Gil Gómez, Pía Martínez, Cubero Marín, Barceló Nicolau, Cerdà Moncadas, Codina Marcet, De La Peña Bravo, Barceló Bennasar, Iglesias Coma, Morell-Garcia, Peña Zarza, Giménez Carrero, Durán Cantolla, Marín Trigo, Piñas Cebrian, Soriano and García-Río. This is an open-access article distributed under the terms of the Creative Commons Attribution License (CC BY). The use, distribution or reproduction in other forums is permitted, provided the original author(s) and the copyright owner(s) are credited and that the original publication in this journal is cited, in accordance with accepted academic practice. No use, distribution or reproduction is permitted which does not comply with these terms. 